|| ISSN(online): 2589-8698 || ISSN(print): 2589-868X ||

International Journal of Medical and Biomedical Studies

Available Online at www.ijmbs.info

NLM (National Library of Medicine ID: 101738825)

Index Copernicus Value 2019: 79.34

Original Research Article

Volume 5, Issue 8; August: 2021; Page No. 40-42

\title{
OCULAR MANIFESTATIONS IN LABORATORY CONFIRMED COVID-19
}

\section{Dr Shakti Krishan Rajguru ${ }^{1}$, Dr. Udesh Rajpurohit ${ }^{2}$}

${ }^{1}$ MBBS, MS, Ophthalmology, Junior Specialist, Department of Ophthalmology, Government Medical College, Barmer, Rajasthan

${ }^{2}$ Junior Resident, Government Medical College, Barmer, Rajasthan

Article Info: Received 29 May 2021; Accepted 02 August 2021

DOI: https://doi.org/10.32553/ijmbs.v5i8.2068

Corresponding author: Dr. Udesh Rajpurohit

Conflict of interest: No conflict of interest.

\section{Abstract}

Background: Scarce literature has been published thus far regarding ocular findings in the COVID-19.

Methods: All patients were confirmed by SARS-CoV-2 real-time reverse transcriptase- polymerase chain reaction (RTPCR) of nasopharynx or oropharynx swab specimens collected at an isolation facility, fever clinic, or hospital unit designated for suspected cases pending confirmation.

Results: Overall, 25 patients (25.00\%) had various ocular symptoms during COVID-19 infection. Among those with ocular symptoms, 19 patients $(76.00 \%)$ presented with increased conjunctival discharge, including white mucoid (6 [24.00\%]), thin watery $(3[12.00 \%])$ and yellow-green purulent $(11[44.00 \%])$ discharge, and with conjunctival congestion (2 [8.00\%]). Other ocular manifestations contained ocular pain (3 [12.00\%]), tearing (1 [4.00\%]), and eyelid swelling (1 [4.00\%]).

Conclusion: We concluded that common ocular manifestations were conjunctival discharge, eye rubbing, and conjunctival congestion.

Keywords: COVID-19, Ocular, Eye.

\section{Introduction}

Since December 2019, coronavirus disease 2019 (COVID-19) has become a global pandemic caused by the highly transmissible severe acute respiratory syndrome coronavirus 2 (SARS-CoV-2). ${ }^{1}$ Initially, there were several reports of eye redness and irritation in COVID-19 patients, both anecdotal and published, suggesting that conjunctivitis is an ocular manifestation of SARS-CoV-2 infection. Reports continue to emerge on further associations of COVID-19 with uveitic, retinovascular, and neuro-ophthalmic disease.

During the 2003 severe acute respiratory syndrome (SARS) outbreak, a study detected SARS-CoV in tear samples in SARS patients in Singapore. ${ }^{2}$ Lack of eye protection was a primary risk factor of SARS-CoV transmission from SARS patients to healthcare workers in Toronto, prompting a concern that respiratory illness could be transmitted through ocular secretions. ${ }^{3,4}$ Similar concerns have been raised with SARS-CoV-2, especially among eye care providers and those on the front lines triaging what could be initial symptoms of COVID-19.

As conjunctivitis is a common eye condition, ophthalmologists may be the first medical professionals to evaluate a patient with COVID-19. Indeed, one of the first providers to voice concerns regarding the spread of coronavirus in Chinese patients was Dr. Li Wenliang, MD, an ophthalmologist. He later died from COVID-19 and was believed to have contracted the virus from an asymptomatic glaucoma patient in his clinic. ${ }^{5-6}$

\section{Material and Method}

Laboratory-confirmed patients with COVID-19 were included in the study. All patients were confirmed by SARS-CoV-2 real-time reverse transcriptase- polymerase chain reaction (RT-PCR) of nasopharynx or oropharynx swab specimens collected at an isolation facility, fever clinic, or hospital unit designated for suspected cases pending confirmation.

The demographic information and clinical manifestations of patients were collected though medical record review, including name, sex, age, exposure history, past medical history, onset of symptoms, admission time, hospital stay, and labtory testing and imaging results. All data were collected and independently reviewed by all research team members. Although some of the data on demographic and clinical characteristics were shared with the other studies, data on the ocular manifestations of the children with COVID-19 have not been reported anywhere else.

Diagnostic criteria of COVID-19 included epidemiology history, clinical manifestations, and etiologicevidence provided by RT-PCR testing. Definitive etiology evidence was required. Asymptomatic patients with COVID-19 were defined as such that the SARS-CoV-2 RT-PCR test 
was positive, but there had been no symptoms before the laboratory confirmation. The severity of the disease was classified according to 7 th edition guideline for diagnosis and treatment of COVID-19.

\section{Data analysis}

Data was recorded as per Performa. The data analysis was computer based; SPSS-22 was used for analysis. For categoric variables chi-square test was used. For continuous variables independent samples's $t$-test was used. $p$-value $<0.05$ was considered as significant.

\section{Results}

A total of 100 patients were included, of which 25 participants $(25.00 \%)$ reported ocular symptoms.

Table 1: Patients characteristics

\begin{tabular}{|l|l|}
\hline Age in yrs & $56.22 \pm 3.16$ \\
\hline Male $:$ Female & $64: 36$ \\
\hline BMI in $\mathrm{kg} / \mathrm{mt}^{2}$ & $23.11 \pm 3.16$ \\
\hline Patients with ocular manifestations & $22 / 100(22.00 \%)$ \\
\hline
\end{tabular}

Table 2: Ocular Manifestations in patients With Confirmed COVID-19 (n=25)

\begin{tabular}{|l|l|}
\hline Conjunctival discharge & $19(76.00 \%)$ \\
\hline White mucoid discharge & $6(24.00 \%)$ \\
\hline Thin watery discharge & $3(12.00 \%)$ \\
\hline Yellow green purulent discharge & $11(44.00 \%)$ \\
\hline Conjuctival congestion & $2(8.00 \%)$ \\
\hline Ocular pain & $3(12.00 \%)$ \\
\hline Tearing & $1(4.00 \%)$ \\
\hline Eyelid swelling & $1(4.00 \%)$ \\
\hline
\end{tabular}

Overall, 25 patients $(25.00 \%)$ had various ocular symptoms during COVID-19 infection. Among those with ocular symptoms, 19 patients $(76.00 \%)$ presented with increased conjunctival discharge, including white mucoid (6 [24.00\%]), thin watery (3 [12.00\%]) and yellow-green purulent (11 [44.00\%]) discharge, and with conjunctival congestion (2 [8.00\%]). Other ocular manifestations contained ocular pain (3 [12.00\%]), tearing (1 [4.00\%]), and eyelid swelling (1 [4.00\%]).

\section{Discussion}

To our knowledge, large case series of ocular manifestations of COVID-19 have not been reported.

Among 100 participants, 25 (25.00\%) experienced ocular symptoms. Although several studies reported the ocular findings in COVID-19, the correlation between ocular symptoms and COVID-19 remain controversial, regardless of ocular detection of SARS-CoV-2..$^{7-9}$ Could SARS-CoV-2 really cause viral conjunctivitis? ${ }^{8}$

Anatomically, the ocular surface (including cornea, conjunctiva, and tear film) communicates with air just like the nasalmucosa. Furthermore, the nasolacrimal duct links the conjunctival sac with the nasal meatus, which could provide the opportunity for the viruses to travel from the respiratory tract to the ocular surfaces. Histologically, angiotensin-converting enzyme 2, which is necessary when SARS CoV-2 infects host cells by the receptor-binding motif, was found to be present in ocular tissues. Whether the ocular disease was directly caused by
SARS-CoV-2 remains unknown, and more studies are needed. ${ }^{10-11}$

However, children with systemic symptoms (eg, fever, cough) appeared more likely to have ocular symptoms. It is plausible that cough can lead to ocular infection through inevitable hand-eye contact in children and/or that the force of cough could push nasopharyngeal secretions from the nasolacrimal duct into the conjunctival sac. ${ }^{12-13}$

\section{Conclusion}

We concluded that common ocular manifestations were conjunctival discharge, eye rubbing, and conjunctival congestion.

\section{References}

1. Cascella M, Rajnik M, Aleem A, Dulebohn SC, Di Napoli R. StatPearls [Internet]. StatPearls Publishing; Treasure Island (FL): Apr 20, 2021. Features, Evaluation, and Treatment of Coronavirus (COVID-19)

2. Loon SC, Teoh SC, Oon LL, Se-Thoe SY, Ling AE, Leo YS, Leong HN. The severe acute respiratory syndrome coronavirus in tears. $\mathrm{Br} \mathbf{J}$ Ophthalmol. 2004 Jul;88(7):861-3

3. Raboud J, Shigayeva A, McGeer A, Bontovics E, Chapman M, Gravel D, Henry B, Lapinsky S, Loeb M, McDonald LC, Ofner M, Paton S, Reynolds D, Scales D, Shen S, Simor A, Stewart 
T, Vearncombe M, Zoutman D, Green K. Risk factors for SARS transmission from patients requiring intubation: a multicentre investigation in Toronto, Canada. PLoS One. 2010 May 19;5(5): e10717.

4. Lu CW, Liu XF, Jia ZF. 2019-nCoV transmission through the ocular surface must not be ignored. Lancet. 2020 Feb 22;395(10224):e39.

5. Seah I, Agrawal R. Can the Coronavirus Disease 2019 (COVID-19) Affect the Eyes? A Review of Coronaviruses and Ocular Implications in Humans and Animals. Ocul Immunol Inflamm. 2020 Apr 02;28(3):391-395

6. Li L, Huang $\mathrm{T}$, Wang $\mathrm{Y}$, Wang Z, Liang Y, Huang $T$, et al. COVID-19 patients' clinical characteristics, discharge rate, and fatality rate of meta-analysis. J Med Virol. 2020;92:577-583. doi: 10.1002/jmv.25757.

7. De Ceano-Vivas M, Martín-Espín I, Del Rosal T, Bueno-Barriocanal M, Plata-Gallardo M, RuizDomínguez JA, et al. SARS-CoV-2 infection in ambulatory and hospitalised Spanish children. Arch Dis Child. 2020;105:808-809. doi: 10.1136/archdischild-2020-319366.

8. Xia J, Tong J, Liu M, Shen Y, Guo D. Evaluation of coronavirus in tears and conjunctival secretions of patients with SARS-CoV-2 infection. J Med
Virol. 2020;92(6):589-594. doi:10.1002/jmv. 25725.

9. Holappa M, Vapaatalo H, Vaajanen A. Many faces of renin-angiotensin system: focus on eye. Open Ophthalmol J. 2017;11:122-142. doi:10.2174/ 1874364101711010122.

10. Wan Y, Shang J, Graham R, Baric RS, Li F. Receptor recognition by the novel coronavirus from Wuhan: an analysis based on decade-long structural studies of SARS coronavirus.J Virol. 2020;94(7): e00127-20. doi:10.1128/JVI.0012720.

11. Zhang BN, Wang Q, Liu T, et al. [Expression analysis of 2019-nCoV related ACE2 and TMPRSS2 in eye tissues]. Zhonghua Yan Ke Za Zhi. 2020;56 (0):E011. doi:10.3760/cma.j.cn 112142-20200310- 00170.

12. Liu L, Sun Y, Pan X, et al Expression of SARS coronavirus sprotein functional receptorangiotensin converting enzyme 2 in human cornea and conjunctiva. Ophthalmic Research. 2004;22 (6): 561-564.

13. Kahbazi M, Fahmizad A, Armin S, et al. Aetiology of upper respiratory tract infections in children in Arak city: a community based study. Acta Microbiol Immunol Hung. 2011;58(4):289-296. 